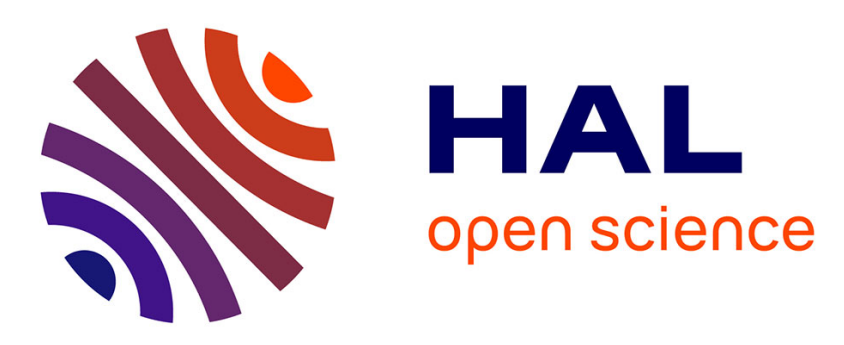

\title{
An improved junction termination design using deep trenches for superjunction power devices
}

Sylvain Noblecourt, Frédéric Morancho, Karine Isoird, Patrick Austin, Josiane

Tasselli

\section{- To cite this version:}

Sylvain Noblecourt, Frédéric Morancho, Karine Isoird, Patrick Austin, Josiane Tasselli. An improved junction termination design using deep trenches for superjunction power devices. International Conference Mixed Design of Integrated Circuits and Systems (MIXDES 2015), Jun 2015, Torùn, Poland. 10.1109/MIXDES.2015.7208583 . hal-01191234

\section{HAL Id: hal-01191234 \\ https://hal.science/hal-01191234}

Submitted on 1 Sep 2015

HAL is a multi-disciplinary open access archive for the deposit and dissemination of scientific research documents, whether they are published or not. The documents may come from teaching and research institutions in France or abroad, or from public or private research centers.
L'archive ouverte pluridisciplinaire HAL, est destinée au dépôt et à la diffusion de documents scientifiques de niveau recherche, publiés ou non, émanant des établissements d'enseignement et de recherche français ou étrangers, des laboratoires publics ou privés. 


\section{An Improved Junction Termination Design Using Deep Trenches for Superjunction Power Devices}

\author{
Sylvain Noblecourt, Frédéric Morancho, Karine Isoird, \\ Patrick Austin \\ Université de Toulouse; CNRS-LAAS \\ Toulouse, France \\ snobleco@laas.fr
}

\author{
Josiane Tasselli \\ CNRS-LAAS \\ Toulouse, France
}

\begin{abstract}
Among the numerous solutions developed to improve the handling capability of superjunction power devices, the Deep Trench Termination $\left(\mathrm{DT}^{2}\right)$ is the most adapted thanks to its lower cost and size compared to other technologies using the multiple epitaxy technique, and an easier implementation in the fabrication process. This paper presents the optimization of the Deep Trench Termination by means of TCAD 2D and 3Dsimulations allowing the realization of deep trench superjunction devices (diodes and MOS transistors) for $1200 \mathrm{~V}$ applications. The work is focused on the influence of the dielectric passivation layer thickness and the field plate length on the breakdown voltage of a DT-SJDiode.
\end{abstract}

Keywords-Deep trench termination; field plate; Superjunction; Breakdown voltage

\section{INTRODUCTION}

Today, the main IGBT competitor is the MOSFET. Indeed, the MOSFET exhibits many interesting properties for power applications: high switching speed, high input impedance and thermal stability. However, in high voltage range $(600 \mathrm{~V}$ and above), conventional MOSFETs are limited by their very high specific on-resistance and, therefore, their high on-state voltage drop, which induces more on-state losses compared to bipolar devices. This on-resistance is inversely proportional to the doping concentration of the drift region, which must be low enough to sustain the off-state voltage: to find the best trade-off between these two parameters (specific on-resistance and breakdown voltage) is one of the major challenges in this voltage range. Recently, numerous researches have been done about the superjunction principle and about the way to realize it. Indeed, this principle allows to overcome the 'breakdown voltage/on-state resistance' trade-off. This technology was chosen in particular by Infineon for the realization of COOLMOS $^{\text {TM }}$ transistors [1] and by STMicroelectronics for the realization of MDMESH $^{\text {TM }}$ devices [2]. However, the manufacturing cost of this technology can be very high because the process requires a multiple epitaxy technique, resulting in a significant number of masks. The deep trench technology [3] is a lower cost alternative with only one epitaxial step. Like all power devices, it needs an adapted junction termination technique to reach the highest breakdown voltage. Several junction termination techniques are available [4]-[6] but our attention has stopped on the deep trench termination, which seems the most adapted termination for this technology. Indeed, one can notice that the junctiontermination area is dramatically decreased compared to conventional junction terminations in this voltage range.

This paper presents in a first part the structure of the Deep Trench SuperJunction Diode (DT-SJDiode) and its associated termination, the Deep Trench Termination $\left(\mathrm{DT}^{2}\right)$. The second part is focused on the Deep Trench Termination parameters in order to obtain the best efficiency in terms of breakdown voltage. Finally, we will present an improvement of the termination that allows an electric field reduction at the critical point and consequently the increase in the breakdown voltage.

\section{STRUCTURE DESCRIPTION}

A cross-sectional view of the proposed DT-SJDiode is presented in Figure 1. It is based on elementary cells allowing the implementation of the superjunction principle [7], i.e. an alternation of $\mathrm{N}$ and $\mathrm{P}$ regions in the volume. To ensure the maximal breakdown voltage, the superjunction is protected in periphery of the active zone by means of a guarding technique developed in the laboratory. We use a dielectric filled wide and deep trench with a field plate on top. The use of deep trenches allows to avoid a multi-epitaxy technology. The $\mathrm{P}^{+}$ region is realized on the trench sidewalls from boron doping by Plasma-Immersion Ionic Implantation (PIII) [8]. The dielectric used is the BCB (Cyclotene 4026-46) [9] whose electrical parameters (critical field of $5.3 \mathrm{MV} . \mathrm{cm}^{-1}$ and dielectric constant of 2.65) allow to ensure the efficiency of the junction termination.

The charge balance between $\mathrm{N}$ and $\mathrm{P}$ regions is important for the proper functioning of the superjunction and thus for the obtaining of an optimal breakdown voltage. Equation (1) recalls this balance in the case of constant doping profiles. Couples $\left(\mathrm{W}_{\mathrm{N}} ; \mathrm{N}_{\mathrm{D}}\right)$ and $\left(\mathrm{W}_{\mathrm{P}} ; \mathrm{N}_{\mathrm{A}}\right)$ represent the widths and the doping concentration of $\mathrm{N}$ and $\mathrm{P}$ regions respectively:

$$
\mathrm{W}_{\mathrm{N}} \cdot \mathrm{N}_{\mathrm{D}}=\mathrm{W}_{\mathrm{P}} \cdot \mathrm{N}_{\mathrm{A}}
$$

To maintain the charge balance, the termination also needs to have a boron implantation on the trench sidewall as shown in Figure 1. 


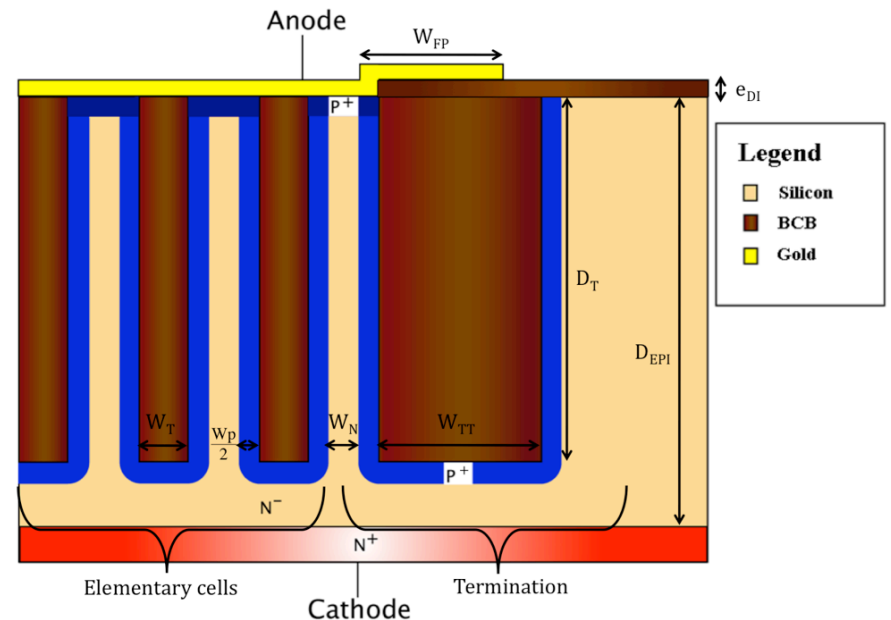

Fig. 1. Schematic cross-section of the DT-SJDiode with its Deep Trench Termination $\left(\mathrm{DT}^{2}\right)$.

A single elementary cell of the DT-SJDiode exhibits a theoretical breakdown voltage of $1350 \mathrm{~V}$. This value was obtained using the same methodology as the one presented in [10]. The corresponding parameters are listed in Table 1. We will use that breakdown voltage as a reference to evaluate the efficiency of the termination. Indeed, the termination efficiency is the ratio between the ideal breakdown voltage (1350 $\mathrm{V}$ in this case) and the breakdown voltage achieved with the termination.

TABLE I. PARAMETERS OF THE SIMULATED STRUCTURE

\begin{tabular}{|l|l|l|}
\hline \multicolumn{1}{|c|}{ Parameters } & \multicolumn{1}{|c|}{ Symbols } & \multicolumn{1}{c|}{ Optimal values } \\
\hline $\begin{array}{l}\mathrm{N}^{-} \text {epitaxial region } \\
\text { doping concentration }\end{array}$ & $\mathrm{N}_{\mathrm{D}}$ & $3 \times 10^{15} \mathrm{~cm}^{-3}$ \\
\hline Implanted P-dose & P-Dose & $10^{12} \mathrm{~cm}^{-2}$ \\
\hline $\begin{array}{l}\text { Distance between two } \\
\text { central trenches }\end{array}$ & $\mathrm{W}_{\mathrm{N}}$ & $6.5 \mu \mathrm{m}$ \\
\hline $\begin{array}{l}\text { P-region width } \\
\text { Central trench width }\end{array}$ & $\mathrm{W}_{\mathrm{P}}$ & $1 \mu \mathrm{m}$ \\
\hline Trench depth & $\mathrm{W}_{\mathrm{T}}$ & $6 \mu \mathrm{m}$ \\
\hline Breakdown voltage & $\mathrm{BV}$ & $1350 \mathrm{~V}$ \\
\hline
\end{tabular}

\section{ANALYSIS OF THE TERMINATION EFFICIENCY}

\section{A. Identification of simulation parameters}

The deep trench termination is characterized by the following geometrical parameters: the depth $\mathrm{D}_{\mathrm{T}}$ and the width $\mathrm{W}_{\mathrm{TT}}$, the length of the field plate $\mathrm{W}_{\mathrm{FP}}$ and the thikness of the passivation layer $e_{D I}$ (see Figure 1). $D_{T}$ is imposed by the depth of the elementary cells trenches: a smaller $\mathrm{D}_{\mathrm{T}}$ induces a charge unbalance, thus decreasing the breakdown voltage; a higher $\mathrm{D}_{\mathrm{T}}$ is not useful because the termination efficiency does not increase. $\mathrm{D}_{\mathrm{T}}$ is fixed to $80 \mu \mathrm{m}$. We focus on the influence of the other geometrical parameters. For all the simulations, a $50 \mu \mathrm{m}$ region of dielectric is added on the top of the structure. Indeed, it is important to study the electrical phenomena occuring on the top of the device for optimizing efficiently the design and the termination. Two limiting criteria are chosen: a leakage current of $10^{-7} \mathrm{~A}$, corresponding to the avalanche breakdown, and an electrical field of $3 \mathrm{MV} . \mathrm{cm}^{-1}$, above which value arcing can occur between the field plate and the termination edges, leading to the destruction of the component.

\section{B. Identification of critical points}

There are two critical points in the structure as schematized on Figure 2. The first one is located at the edge of the field-plate (point A) where the potential lines shrink, inducing a maximum electric field, compared to the rest of the structure. The point $\mathrm{B}$ represents the place where the avalanche phenomenon appears, especially if the length of the field plate is small. Indeed, the purpose of the termination is to distribute the electrical potential lines in the dielectric to approach the ideal breakdown voltage. If the length of the field plate is not long enough, the electrical potential lines are concentrated close to the silicon, thus increasing the electrical field, and finally inducing a premature avalanche breakdown.

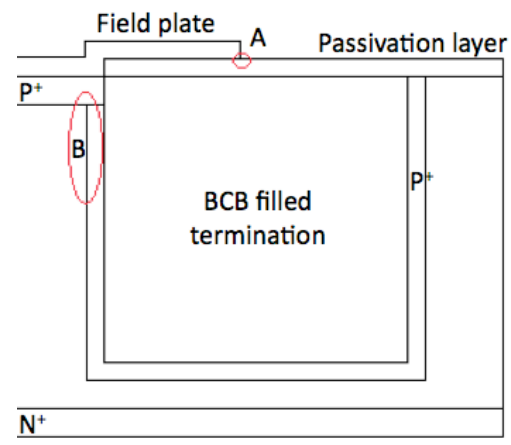

Fig. 2. Schematic view of the critical points for the breakdown.

\section{Influence of the geometrical parameters}

We have first studied the influence of the field-plate length on the breakdown voltage for various termination trench widths, as shown on Figure 3.

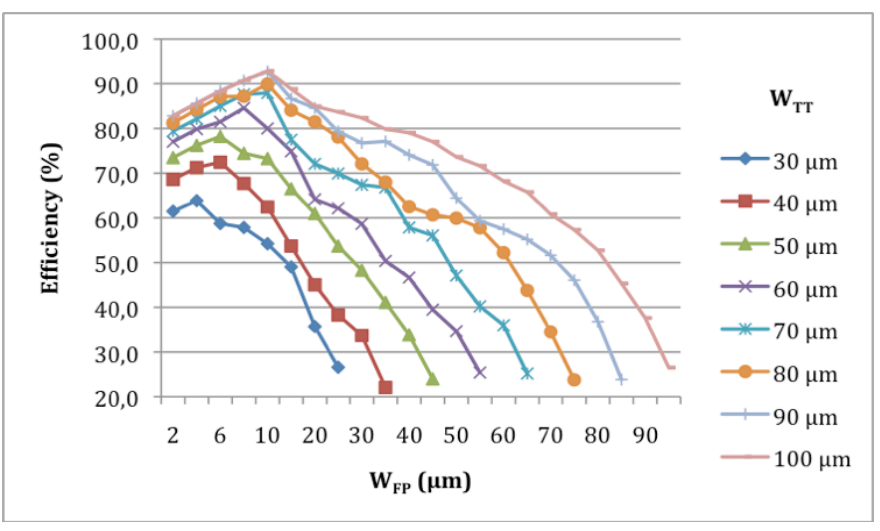

Fig. 3. Variations of the termination efficiency as a function of $W_{F P}$ for various values of the termination trench width $\mathrm{W}_{\mathrm{TT}}$. 
Increasing $\mathrm{W}_{\mathrm{TT}}$ increases the breakdown voltage. For $\mathrm{W}_{\mathrm{FP}}$ fixed at $10 \mu \mathrm{m}$, and for $\mathrm{W}_{\mathrm{TT}}$ values varying from $30 \mu \mathrm{m}$ to 70 $\mu \mathrm{m}$, the efficiency increases from $55 \%$ to near $90 \%$. Above $80 \mu \mathrm{m}$, the termination efficiency can reach and exceed $90 \%$. However the efficiency increase is not significant: so the optimal value for the termination width is $80 \mu \mathrm{m}$. We can also see on Figure 3 that there is an optimal value of $\mathrm{W}_{\mathrm{FP}}$, depending on $\mathrm{W}_{\mathrm{TT}}$. At first, increasing $\mathrm{W}_{\mathrm{FP}}$ increases the breakdown voltage until the optimal value. More the edge of the field plate is close to the last central cell, more the breakdown is premature. Beyond the optimal value, increasing $\mathrm{W}_{\mathrm{FP}}$ has a negative impact on the electric field due to the reduction of the potential line spacing as shown on Figure 4. The consequence is an increase in the electrical field at the point A. Indeed, all simulations here stop because the electric field is $3 \mathrm{MV} \cdot \mathrm{cm}^{-1}$. The problem is that if the breakdown voltage is due to the electric field, it is destructive for the component.
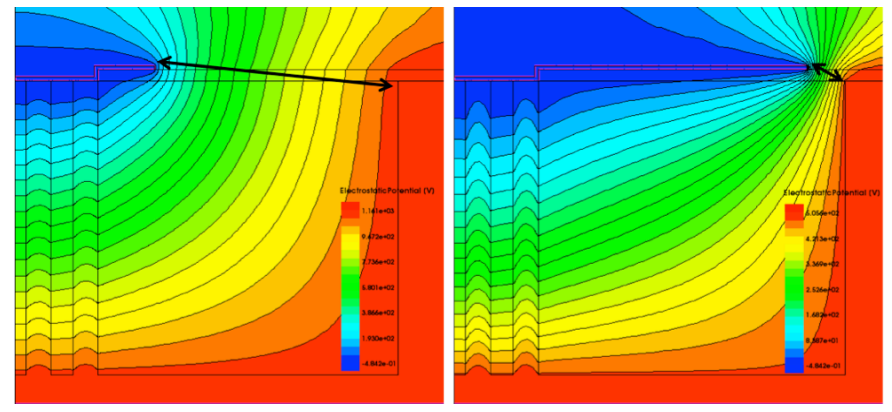

Fig. 4. 2D-simulated electrostatic potential distribution in the deep trench termination for $\mathrm{W}_{\mathrm{FP}}=15 \mu \mathrm{m}$ (on the left) and $\mathrm{W}_{\mathrm{FP}}=70 \mu \mathrm{m}$ (on the right).

Figure 5 shows the influence of the dielectric thickness on the termination efficiency for $\mathrm{W}_{\mathrm{TT}}=80 \mu \mathrm{m}$ and $\mathrm{W}_{\mathrm{FP}}=10 \mu \mathrm{m}$. Increasing the $\mathrm{BCB}$ thickness does not permit an increase in the breakdown voltage because it decreases the electric field at point $\mathrm{A}$ and the limiting parameter is the leakage current for this point. However, the presence of dielectric is necessary for preventing arcing between the field plate and the termination edges. It can be noticed that there is a slight drop of the efficiency when $e_{D I}$ increases. Indeed, increasing $e_{D I}$ stray the field plate and reduce its effect.

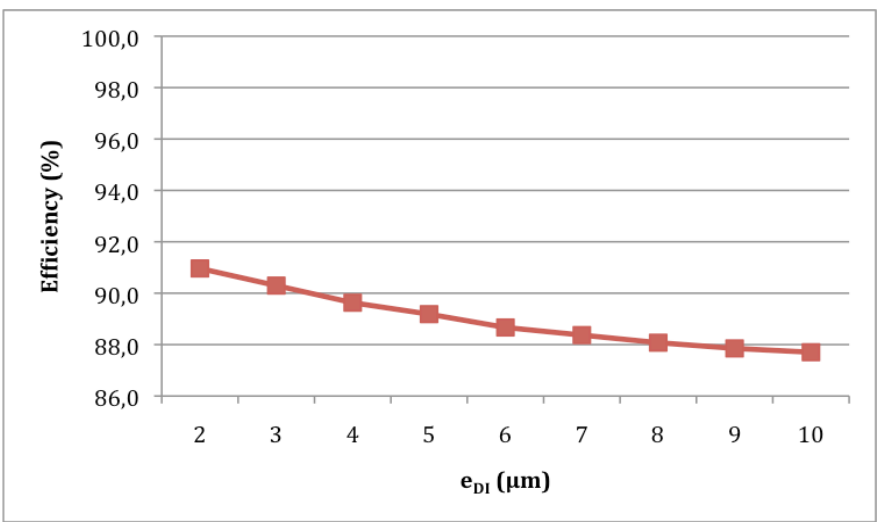

Fig. 5. Variation of the termination efficiency with the dielectric thickness $\mathrm{e}_{\mathrm{DI}}$ for $\mathrm{W}_{\mathrm{TT}}=80 \mu \mathrm{m}$ and $\mathrm{W}_{\mathrm{FP}}=10 \mu \mathrm{m}$.
Finally, the geometrical parameter values that provide the best trade-off "efficiency/size" are $\mathrm{W}_{\mathrm{TT}}=80 \mu \mathrm{m}$, $\mathrm{W}_{\mathrm{FP}}=10 \mu \mathrm{m}$ (the field plate length depending on the termination trench width) and $\mathrm{e}_{\mathrm{DI}}=1 \mu \mathrm{m}$.

\section{IMPROVEMENT OF THE TERMINATION}

\section{A. Description of the new design}

In order to improve the efficiency of the termination and to decrease the electric field at the point $\mathrm{A}$, we propose to add a thickness of dielectric $\mathrm{e}_{\mathrm{DI}-\mathrm{FP}}$ only under the field plate as illustrated on Figure 6. Here, we use BCB for this layer because it can be easily integrated in our fabrication process. The stair-step allows a better potential distribution.

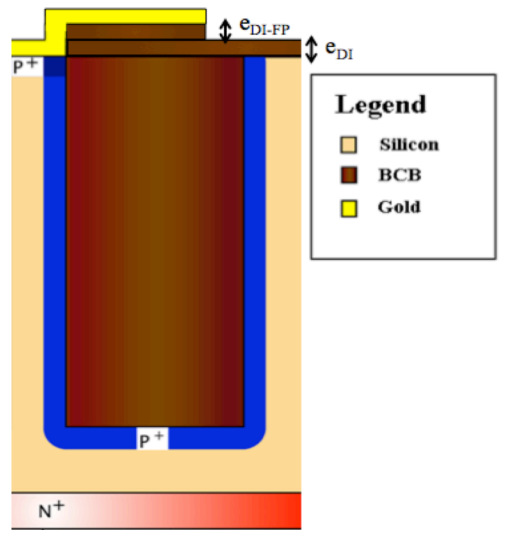

Fig. 6. Schematic cross-section of the improved termination.

Figure 7 compares the evolution of the termination efficiency as a function of the field plate length $\mathrm{W}_{\mathrm{FP}}$ for two structures: the one with dielectric above the whole junction termination as schematized on Figure 1 (previous design) and the other with an added BCB dielectric only under the field plate (new design shown on Figure 6). The BCB thicknesses $\mathrm{e}_{\mathrm{DI}}$ and $\mathrm{e}_{\mathrm{DI}-\mathrm{FP}}$ are fixed at $1 \mu \mathrm{m}$ and the termination width is fixed at $80 \mu \mathrm{m}$.

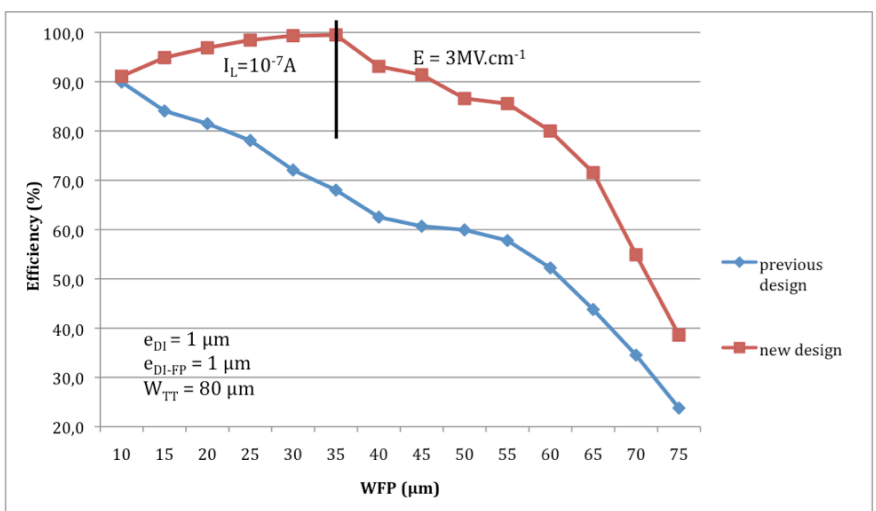

Fig. 7. Influence of the structure design on the termination efficiency as a function of the field plate length $\mathrm{W}_{\mathrm{FP}}$.

The new structure allows to reach almost $100 \%$ of the termination efficiency. For $\mathrm{W}_{\mathrm{FP}}<35 \mu \mathrm{m}$, there is an avalanche breakdown occurring at the point $\mathrm{B}$ which is not destructive for the device. For $\mathrm{W}_{\mathrm{FP}}>35 \mu \mathrm{m}$, the electrical field reaches 
$3 \mathrm{MV} . \mathrm{cm}^{-1}$ at the point A before the avalanche phenomenon at the point $B$. Thus, there is an optimal value of $W_{F P}$ which is $35 \mu \mathrm{m}$.

In this new design, the BCB thickness under the field plate, $\mathrm{e}_{\mathrm{DI}-\mathrm{FP}}$, has an impact on the electrostatic potential lines distribution. Indeed, increasing this layer extends the area of the potential distribution. Figure 8 represents the termination efficiency evolution as a function of $\mathrm{W}_{\mathrm{FP}}$ for various values of $\mathrm{e}_{\mathrm{DI}-\mathrm{FP}}$ : the maximum termination efficiency is the same whatever $\mathrm{e}_{\mathrm{DI}-\mathrm{FP}}$. Note that all the simulations stopped because of the leakage current. For each curve, increasing $\mathrm{W}_{\mathrm{FP}}$ beyond the maximal value represented on Figure 8 means a drop of the efficiency due to the electric field reaching $3 \mathrm{MV} . \mathrm{cm}^{-1}$.

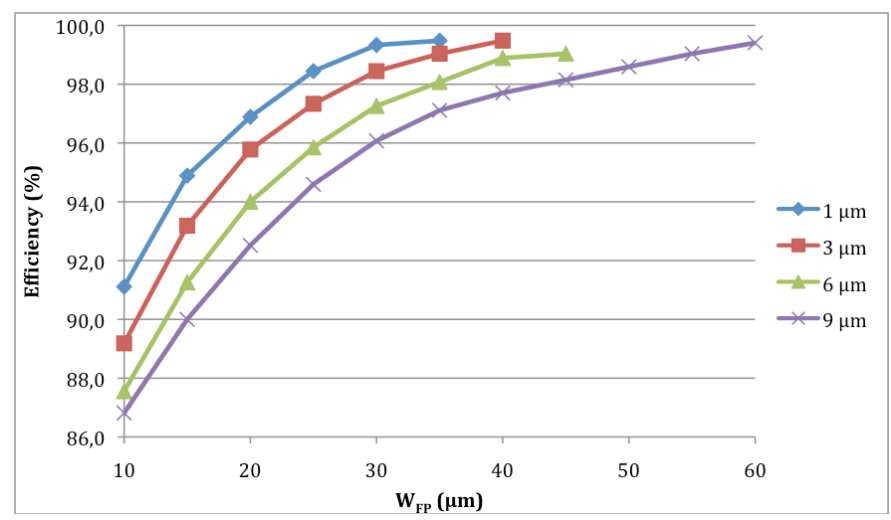

Fig. 8. Variations of the termination efficiency as a function of the field plate length $\mathrm{W}_{\mathrm{FP}}$ for various values of $\mathrm{e}_{\mathrm{DI}-\mathrm{FP}}$.

\section{B. $3 D$ Simulations}

3D simulations have been performed in order to verify the efficiency at the edges of the device. Indeed, it is well-known that cylindrical and spherical junctions induce premature breakdown [11]. A schematic top view and a $3 \mathrm{D}$ view of the simulated structure are reported on Figure 9.
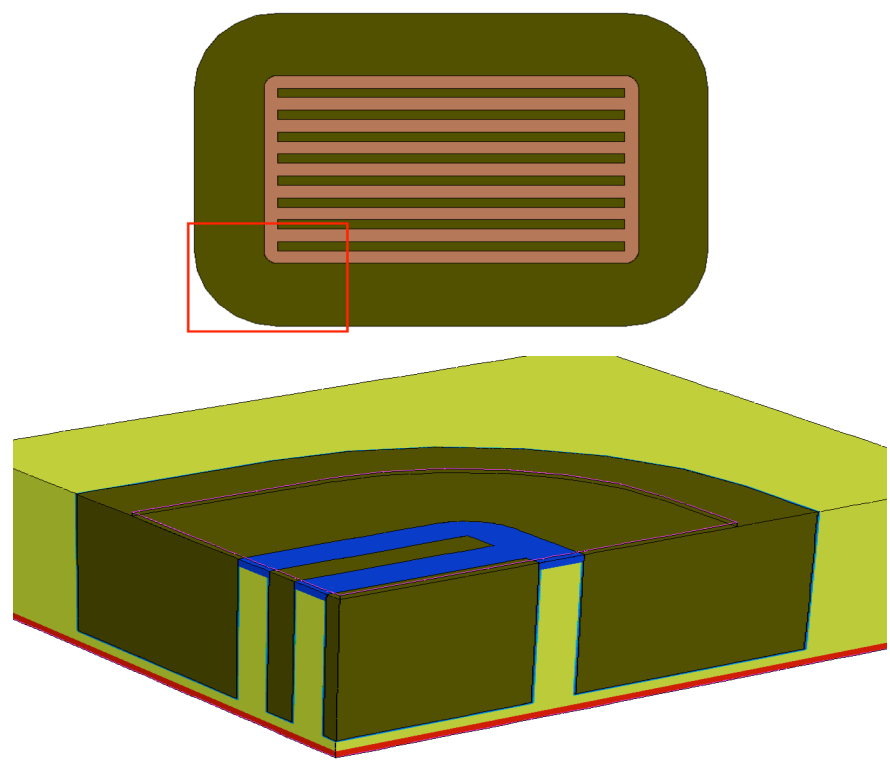

Fig. 9. Schematic top view and 3D view of the simulated structure.
In $2 \mathrm{D}$, the distance between the termination and the last elementary cell must be equal to the distance between two elementary cells in order to maintain the charge balance. In the case of 3D simulations and with the optimized parameters reported in Table 1, a premature breakdown occurs because there is an unbalance charge in the regions located at the corners of the rectangular elementary cells. This phenomenom is illustrated on Figure 10 that shows the repartition of the impact ionization: in $3 \mathrm{D}$, the equation (1) is no more valid because it is necessary to encompass the volume. The equation of the charge balance becomes the following one :

$$
\mathrm{V}_{\mathrm{N}} \cdot \mathrm{N}_{\mathrm{D}}=\mathrm{V}_{\mathrm{P}} \cdot \mathrm{N}_{\mathrm{A}}
$$

Couples $\left(\mathrm{V}_{\mathrm{N}} ; \mathrm{N}_{\mathrm{D}}\right)$ and $\left(\mathrm{V}_{\mathrm{P}} ; \mathrm{N}_{\mathrm{A}}\right)$ represent the volumes and the doping concentrations of $\mathrm{N}$ and $\mathrm{P}$ regions respectively.

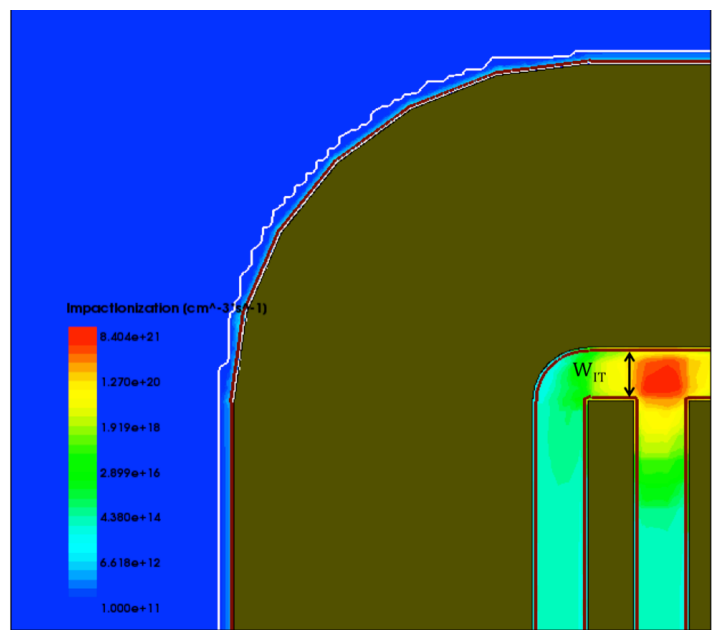

Fig. 10. Cross section of the 3D simulated structure showing the point where the avalanche phenomenon occurs. The colors represent the impact ionisation distribution.

The breakdown voltage is $71 \%$ of the maximal breakdown voltage related to central cells without correction. According to equation (2), the four parameters involved are key parameters for the charge balance. In our case, the $\mathrm{P}$ sidewall regions are realized by ionic implantation, so the term " $\mathrm{V}_{\mathrm{P}} \times \mathrm{N}_{\mathrm{A}}$ " can not be changed. In the same way, $\mathrm{N}_{\mathrm{D}}$ can not be changed. The only parameter we can act on is $\mathrm{W}_{\text {IT }}$, i.e. the spacing between the elementary cells and the termination at the corner side (see Figure 10), which parameter the $\mathrm{V}_{\mathrm{N}}$ volume depends on. From equation (2), it results that the optimal $\mathrm{W}_{\mathrm{IT}}$ value for obtaining the charge balance is approximately $4.5 \mu \mathrm{m}$. In order to optimize $\mathrm{W}_{\mathrm{IT}}$, the leakage current is the only one limiting criterion used for the 3D simulations. Starting from a $\mathrm{W}_{\text {IT }}$ value of $6.5 \mu \mathrm{m}$, we have studied the termination efficiency variations for different values of $\mathrm{W}_{\text {IT }}$ reduction. It can be seen on Figure 11 that a $\mathrm{W}_{\text {IT }}$ decrease allows to approach the charge balance and so to obtain a better termination efficiency. However, a $\mathrm{W}_{\mathrm{IT}}$ decrease unbalances the charge in the corner of the 
termination. Thus, there is an optimal value of $\mathrm{W}_{\mathrm{IT}}$ to obtain the better termination efficiency. A $2 \mu \mathrm{m} \mathrm{W}_{\mathrm{IT}}$ reduction improves the breakdown voltage and the termination efficiency becomes equal to $97 \%$.

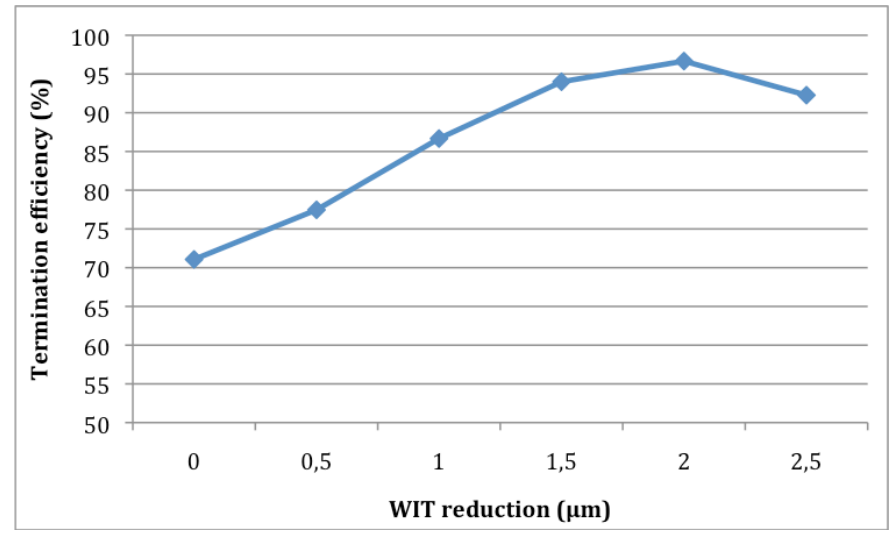

Fig. 11. Variation of the termination efficiency for various values of $\mathrm{W}_{\mathrm{IT}}$ reduction.

\section{CONCLUSION}

In this work, we have proposed a new Deep Trench Termination design allowing the realization of deep trench superjunction devices (diodes and MOS transistors) for $1200 \mathrm{~V}$ applications. 2D and 3D simulations have permitted to evaluate the influence of the geometrical parameters on the termination efficiency. Increasing the field plate length $\mathrm{W}_{\mathrm{FP}}$ has a negative impact on the breakdown voltage because it tightens the potential distribution : the breakdown is always located at the end of the termination which is destructive for the component. A modification of the structure was proposed to improve the efficiency until almost $100 \%$ and to allow an avalanche breakdown phenomenon which is not destructive.

The new design consists in the addition of a dielectric layer under the field plate thus allowing a better potential distribution. The $3 \mathrm{D}$ simulations permit to highlight a charge balance issue at the corners of the elementary cells and to optimize the structure design. The realization of DT-SJDiode is on going.

\section{ACKNOWLEDGMENT}

This work was partly supported by the French RENATECH Network and the French National Research Agency under reference ANR-2011-B509-033 ("SUPERSWITCH” project)

\section{REFERENCES}

[1] L. Lorenz, G. Deboy, A. Knapp, M. März, "COOLMOS'm - a new milestone in high voltage power MOSFET”, ISPSD'99, pp. 3-10.

[2] M. Sagio, D. Fagone, S. Musumeci, "MDMESH"м: innovative technology for high voltage power MOSFETs", ISPSD'2000, pp. 65-68.

[3] K. Takahashi et al., " $2 \mathrm{Om} \Omega \mathrm{cm}^{2} 660 \mathrm{~V}$ Super Junction MOSFETs fabricated by Deep Trench Etching and Epitaxial Growth", ISPSD 2006, pp. 1-4.

[4] L. Théolier, H. Mahfoz-Kotb, K. Isoird, F. Morancho, "A new junction termination technique: the Deep Trench Termination $\left(\mathrm{DT}^{2}\right)$ ", ISPSD 2009, pp. 176-179.

[5] R. Miao, F. Lu, Y. Wing, D. Wei, "Deep oxide trench termination structure for super-junction MOSFET”, Electronics letters, vol. 47, n ${ }^{\circ} 6$ 2012 .

[6] K. Seto, R. Kamibaba, M. Tsukuda, I. Omura, "Universal Trench Edge Termination Design,” ISPSD 2012, pp.161-164.

[7] T. Fujihira, "Theory of semiconductor superjunctions devices", Japanese Journal of Applied Physics, Vol. 36, pp. 6254-6262, 1997.

[8] S. Nizou, V. Vervisch, H. Etienne, M. Ziti, F. Torregrosa, L. Roux, M. Roy, D. Alquier, "Deep Trench doping by plasma immersion ion implantation in silicon", 16th International conference on Ion Implantation Technology 2006, Marseille, pp. 229-232, 11-16 June 2006.

[9] Dow Chemical Company Processing for CYCLOTENE 4000 Series Photo BCB Resins, Febrary 2005.

[10] S. Noblecourt et al., "Optimisation de la diode à Superjonction à tranchées profondes à 600V", SGE' 2014 (EF-EPF-MGE 2014) 8-10 July, Cachan.

[11] S. C. Sun, "Physics and technology of power MOSFET's", Ph. D Thesis, Standford University, 1982. 